\title{
Physical inactivity as a determinant of the physical activity level in the elderly.
}

Citation for published version (APA):

Meijer, E. P., Goris, A. H. C., Wouters, J. L. J., \& Westerterp, K. R. (2001). Physical inactivity as a determinant of the physical activity level in the elderly. International Journal of Obesity, 25, 935-939. https://doi.org/10.1038/sj.ijo.0801644

Document status and date:

Published: 01/01/2001

DOI:

10.1038/sj.ijo.0801644

Document Version:

Publisher's PDF, also known as Version of record

Document license:

Taverne

\section{Please check the document version of this publication:}

- A submitted manuscript is the version of the article upon submission and before peer-review. There can be important differences between the submitted version and the official published version of record.

People interested in the research are advised to contact the author for the final version of the publication, or visit the DOI to the publisher's website.

- The final author version and the galley proof are versions of the publication after peer review.

- The final published version features the final layout of the paper including the volume, issue and page numbers.

Link to publication

\footnotetext{
General rights rights.

- You may freely distribute the URL identifying the publication in the public portal. please follow below link for the End User Agreement:

www.umlib.nl/taverne-license

Take down policy

If you believe that this document breaches copyright please contact us at:

repository@maastrichtuniversity.nl

providing details and we will investigate your claim.
}

Copyright and moral rights for the publications made accessible in the public portal are retained by the authors and/or other copyright owners and it is a condition of accessing publications that users recognise and abide by the legal requirements associated with these

- Users may download and print one copy of any publication from the public portal for the purpose of private study or research.

- You may not further distribute the material or use it for any profit-making activity or commercial gain

If the publication is distributed under the terms of Article $25 \mathrm{fa}$ of the Dutch Copyright Act, indicated by the "Taverne" license above, 


\title{
Physical inactivity as a determinant of the physical activity level in the elderly
}

\author{
EP Meijer ${ }^{1 *}$, AHC Goris ${ }^{1}$, L Wouters $^{1}$ and KR Westerterp ${ }^{1}$ \\ ${ }^{1}$ Department of Human Biology, Maastricht University, Maastricht, The Netherlands
}

OBJECTIVE: To assess the relationship between the mean physical activity level (PAL) and the time spent on activities of three different intensity levels in an elderly population. Data was compared with previously obtained data from a group of younger adults.

SUBJECTS: Fourteen elderly women and 14 elderly men $\left(61 \pm 4 \mathrm{y} ; 27 \pm 5 \mathrm{~kg} / \mathrm{m}^{2} ; 33 \pm 7 \%\right.$ body fat), and 14 young women and 16 young men $\left(27 \pm 5 \mathrm{y}, 24 \pm 2 \mathrm{~kg} / \mathrm{m}^{2}\right)$.

MEASUREMENTS: PAL was determined as average daily metabolic rate (ADMR) combined with a measurement of basal metabolic rate (BMR): $P A L=A D M R / B M R$. $A D M R$ was measured with the doubly labeled water method. BMR was measured with a ventilated hood system. Time spent on activity and activity intensity was measured by using a tri-axial accelerometer $(7 \times 2 \times 0.8 \mathrm{~cm}, 30 \mathrm{~g})$ over a 2 week interval.

RESULTS: Mean PAL was $1.65 \pm 0.14$. PAL was inversely related to the percentage of time spent on low-intensity activity (lying, sitting and standing), $r=-0.43 ; P<0.05$. Older subjects spent significantly more time at these activities than 20 to 35 -y-old subjects $(82 \pm 7 \%$ vs $65 \pm 7 \% ; P<0.0001)$. A significant relation was not observed between PAL and the percentage of time spent on moderate (walking) or high (household activities, exercise and sports) intensity activity, or activity monitoring time $(14.4 \pm 1.2 \mathrm{~h} /$ day $)$.

CONCLUSION: In the elderly, spending relatively more time on low-intensity activities affects the mean PAL negatively. To obtain a higher PAL does not necessarily imply high-intensity activities like sports.

International Journal of Obesity (2001) 25, $935-939$

Keywords: doubly labeled water; tri-axial accelerometer

\section{Introduction}

Regular physical activity is an important contributor to a healthy lifestyle in the prevention of chronic disease. ${ }^{1}$ Aging, however, is associated with a decline in physical activity level. $^{2,3}$ Therefore, exercise programs for the elderly are promoted to improve or maintain physical fitness and health. Goran and Poehlman, ${ }^{4}$ however, showed that in elderly subjects training did not result in an increase in average daily metabolic rate (ADMR) as measured with the

*Correspondence: EP Meijer, Department of Human Biology, Maastricht University, PO Box 616, 6200 MD Maastricht, The Netherlands.

E-mail: e.meijer@hb.unimaas.nl

Received 18 July 2000; revised 9 November 2000;

accepted 23 January 2001 doubly labeled water method. The imposed training activity was compensated for by a corresponding decline in nontraining physical activity. Goran and Poehlman ${ }^{4}$ speculated that the level of exercise, $3 \mathrm{~h} /$ week at $85 \% \mathrm{VO}_{2 \max }$, was too vigorous and thus fatigued the elderly participants during the remainder of the day. Recently, however, we ${ }^{5}$ showed the same compensatory effect of exercise training on nontraining physical activity in elderly subjects, with a training program of only moderate intensity ( $\left.\sim 40 \% \mathrm{VO}_{2 \max }\right)$. It was shown that elderly subjects anticipate the training program by lowering their physical activity even before the exercise training session. Non-training physical activity was measured directly by using tri-axial accelerometers.

Tri-axial accelerometers, as used in the previous study, are an objective and reliable tool to assess the physical activity level in free-living subjects. ${ }^{6}$ Additionally, accelerometers allow assessment of physical activity in large populations over periods that are long enough to be representative for normal daily life and with minimal discomfort for the 
subjects. ${ }^{7}$ Comparison between physical activity generated accelerometer output and activity associated energy expenditure as measured with doubly labeled water in 30 freeliving subjects over 7 day intervals revealed a significant relationship $(r=0.80){ }^{8}$ These tri-axial accelerometers are not only capable of measuring the physical activity pattern but also the intensity of movement.

The first purpose of the present study was to assess the relationship between the mean physical activity level and the time spent on activities of three different intensity levels (low-, moderate- and high-intensity activities, respectively). Secondly, previously obtained data from a group of younger adults was used to examine possible age-associated differences in time spent on the three intensity levels. The physical activity level was assessed with the doubly labeled water method simultaneously with the use of tri-axial accelerometers.

\section{Methods \\ Subjects}

Twenty-eight healthy sedentary men and women participated in the study. Subjects were recruited from advertisements in the local media. Selection criteria were age over $55 \mathrm{y}$, no health problems, and no medication known to affect energy metabolism. Detailed information concerning the purpose and methods used in the study was provided, and written consent was obtained. The Ethics Committee of Maastricht University approved the study. Subject characteristics are shown in Table 1.

\section{Study design}

The study included a 2 week observation period for the measurement of average daily metabolic rate (ADMR) and physical activity level (PAL).

\section{Physical characteristics}

Body mass was measured on an electronic scale (Sauter, Type E1200, Ebingen, Germany). Body composition was calculated from body mass, body volume and total body water (TBW) using Siri's three-compartment model. ${ }^{9}$ Body volume

Table 1 Subject characteristics (mean \pm s.d.)

\begin{tabular}{lcc}
\hline & Elderly & Young adults \\
\hline $\mathrm{n}$ (women/men) & $28(14 / 14)$ & $30(14 / 16)$ \\
Age $(\mathrm{y})$ & $61 \pm 4$ & $27 \pm 5$ \\
Body mass $(\mathrm{kg})$ & $77 \pm 12$ & $72 \pm 11$ \\
$\mathrm{BMl}\left(\mathrm{kg} / \mathrm{m}^{2}\right)$ & $27 \pm 5$ & $24 \pm 2$ \\
Body fat $(\%)$ & $33 \pm 7$ & - \\
$\mathrm{VO}_{2 \max }(\mathrm{ml} / \mathrm{kg} / \mathrm{min})$ & $24 \pm 7$ & - \\
$\mathrm{W}_{\max }(\mathrm{W})$ & $148 \pm 47$ & - \\
\hline
\end{tabular}

BMI, body mass index; $\mathrm{VO}_{2 \max }$ maximal oxygen consumption; $W_{\text {max }}$ maximal workload capacity. was determined by underwater weighing. Residual lung volume was measured simultaneously using the helium dilution technique (Volugraph 2000, Mijnhardt, Bunnik, The Netherlands). TBW was determined using deuterium $\left({ }^{2} \mathrm{H}_{2} \mathrm{O}\right)$ dilution. Maximal workload capacity $\left(\mathrm{W}_{\max }\right)$ and maximal oxygen uptake $\left(\mathrm{VO}_{2 \max }\right)$ were measured, on an electronically braked cycle ergometer (Lode Excalibur, Groningen, The Netherlands) during an incremental exercise test, as described before. ${ }^{5}$

\section{Energy expenditure}

ADMR was measured with the doubly labeled water method according to the Maastricht protocol. ${ }^{10}$ Subjects were given, on the evening of day 0 after a background urine sample was collected, a weighed dose of a mixture of 99.9 atom $\%{ }^{2} \mathrm{H}_{2} \mathrm{O}$ in 10.0 atom $\% \mathrm{H}_{2}{ }^{18} \mathrm{O}$, such that baseline levels were increased to $\geq 300 \mathrm{ppm}$ for ${ }^{2} \mathrm{H}$ and $\geq 2300 \mathrm{ppm}$ for ${ }^{18} \mathrm{O}$. Additionally, urine samples were collected on day 1 (from second void) on the evening of day 1 , evening of day 7 , morning day 8 (from second void), evening of day 14 , and morning of day 15 (from second void). Mean physical activity level was determined as ADMR combined with a measurement of basal metabolic rate $(\mathrm{BMR}): \mathrm{PAL}=\mathrm{ADMR} / \mathrm{BMR}$.

\section{Basal metabolic rate}

BMR was measured after an overnight fast at 6.45 am After a period of $15 \mathrm{~min}$ bed-rest under thermoneutral temperature conditions, BMR was measured for at least $15 \mathrm{~min}$. Oxygen consumption and carbon dioxide production were measured by means of a computerized, open-circuit, ventilated hood system. Gas analyses were performed using a paramagnetic oxygen analyzer (Servomex Type 500 A, Crowborough Sussex, UK) and an infrared carbon dioxide analyzer (Servomex Type 12-X1). The system was similar to the analysis system for the respiration chambers described before. ${ }^{11}$ Calculation of BMR was based upon the Weir formula. ${ }^{12}$

\section{Daily physical activity}

Physical activity over a 14 day interval was registered by using a tri-axial accelerometer, consisting of three uni-axial piezo-electric accelerometers, attached to the lower back of the subjects with an elastic belt. The tri-axial accelerometer was the same version $(7 \times 2 \times 0.8 \mathrm{~cm}, 30 \mathrm{~g})$ as described recently. ${ }^{7}$ The accelerometer calculates the sum of the rectified and integrated acceleration curves from the anteroposterior, medio-lateral and longitudinal axis of the trunk. The time period for integration was set at $1 \mathrm{~min}$. Subjects were instructed to wear the accelerometer during waking hours, except during bathing and showering. Activities were defined in three intensity levels, as validated against indirect calorimetry. ${ }^{6}$ Low-intensity, associated with an accelerometer output $\leq 200$ counts/min, represents lying, sitting and standing ( $<3$ METs (work metabolic rate/resting meta- 
bolic rate)). Moderate-intensity, associated with an accelerometer output ranging from 200 to 500 counts/min, includes walking (3-6 METs). High-intensity, associated with an accelerometer output $\geq 500$ counts/min, includes household activities, exercise and sports ( $>6$ METs). The fraction of time spent on a certain intensity level was calculated as time spent on the intensity level divided by the total activity time.

Accelerometer data of the elderly subjects was compared with previously obtained accelerometer data of healthy nonobese younger adults (14 women and 16 men; $27 \mathrm{y}$ (range $20-35 \mathrm{y}) ; 24 \pm 2 \mathrm{~kg} / \mathrm{m}^{2}$ ), applying an earlier version of the accelerometer used in the present study. ${ }^{6}$ Definition of the three intensity levels was identical for the two studies, which allows direct comparison of the data. The absolute intensity cut-off points, however, were adjusted for difference in age, which was determined by using the same validation test for the elderly subjects as was done for the younger subjects. ${ }^{6}$

\section{Statistics}

Data are presented as means \pm s.d. Paired $t$-tests (two-tailed) with Bonferroni correction were used to evaluate differences within subjects, while differences between subjects were evaluated with unpaired $t$-tests with Bonferroni correction. Simple regression was used to examine the relationship between PAL and the three different activity intensities. Correlations are Pearson product-moment correlations. Statistical significance was accepted as $P<0.05$. The StatView5.0 program (1992-1998, SAS Institute Inc., Cary, NC, USA) was used as the statistical package.

\section{Results}

The mean PAL was $1.65 \pm 0.14$ (Table 2), and PAL was significantly correlated with accelerometer output (Figure $1 ; r=0.78 ; P<0.0001)$. PAL was significantly associated with $\mathrm{VO}_{2 \max }$ adjusted for differences in fat-free mass $(r=0.59 ; P<0.0001)$. PAL was inversely related to the percentage of time spent on low-intensity activities $(r=-0.43$;

Table 2 Daily sleeping time, activity monitoring time, physical activity level (PAL), and the percentage of time spent on activities of low-, moderate- and high-intensity. Data of younger adults obtained from Bouten et $\mathrm{al}^{6}$

\begin{tabular}{|c|c|c|c|c|}
\hline \multirow[b]{2}{*}{ Variable (unit) } & \multicolumn{2}{|c|}{ Elderly } & \multicolumn{2}{|c|}{ Younger adults } \\
\hline & Mean & Range & Mean & Range \\
\hline Sleeping time (h/day) & 8.5 & $6.4-11.5$ & 8.3 & $6.7-10.5$ \\
\hline Activity time (h/day) & 14.4 & $11.7-17.2$ & 13.7 & $10.9-16.1$ \\
\hline PAL & $1.65^{*}$ & $1.44-2.0$ & 1.77 & $1.51-2.04$ \\
\hline Low activity (\%) & $82^{\star \star}$ & $66-95$ & 65 & $52-82$ \\
\hline Moderate activity (\%) & $15^{\star *}$ & $3-22$ & 25 & $11-36$ \\
\hline High activity (\%) & $4^{\star *}$ & $1-12$ & 9 & $3-15$ \\
\hline
\end{tabular}

${ }^{\star} P<0.01 ;{ }^{* \star P} P<0.0001$.

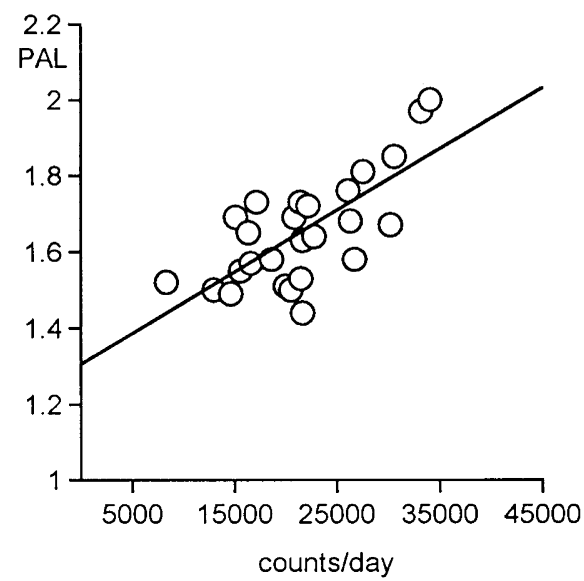

Figure 1 Physical activity level (PAL) as measured with the doubly labeled water method vs accelerometer output in counts/day. $\mathrm{PAL}=0.0002 \times$ accelerometer output $+1.30 ; r=0.78 ; P<0.0001$.

$P<0.05)$. No significant relationship was observed between PAL and the percentage of time spent on high-intensity activities $(r=0.38 ; P=0.15)$. The relationship between PAL and the percentage of time spent on moderate activity intensities just failed to reach significance $(r=0.37$; $P=0.07$ ). Elderly subjects spent significantly more time on low-intensity activities than on moderate- or high-intensity activities $(P<0.0001$; Figure 2$)$. Furthermore, elderly subjects spent significantly more time on low-intensity activities than younger adults $(82 \pm 7 \%$ vs $65 \pm 7 \% ; P<0.0001$; Figure $2)$. The opposite was shown with moderate- and highintensity activities: elderly spent significantly less of their

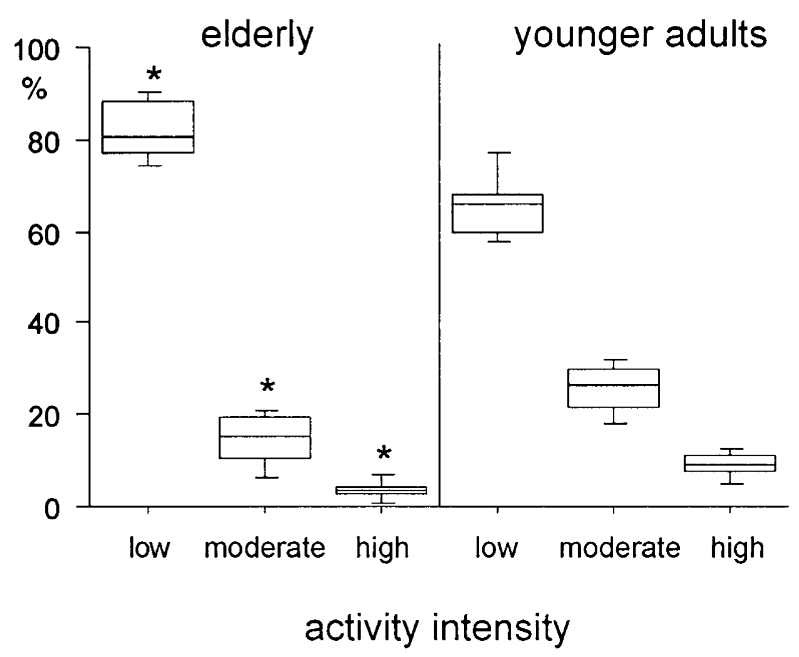

Figure 2 Box-and-whisker plots (median with quartiles and range) of the percentage of time spent on activities with low-, moderate- and highintensity of elderly (left side) and younger adults (right side). Significantly different between elderly and younger adults, ${ }^{\star} P<0.0001$. 
time on moderate- and high-intensity activities than younger adults $(P<0.0001)$. No significant differences were observed between elderly and younger adults in activity monitoring time or sleeping time (Table 2).

\section{Discussion}

The present study shows that, in an elderly population, spending relatively more time on low-intensity activities affects the mean PAL negatively. To obtain a higher PAL does not necessarily imply high-intensity activities like sports.

In this study PAL was inversely related to the time spent on low-intensity activities $(r=-0.43, P<0.05)$. The relationship between time spent on moderate-intensity activities and PAL just failed to reach significance $(r=0.37 ; P=0.07)$, which could be due to the small number of subjects in this study $(n=28)$. In addition, the study with the younger adults showed a strong correlation between PAL and time spent on low- or moderate-intensity activities $(r=-0.67, P<0.0001$; $r=0.70, P<0.0001$, respectively). The results of both studies clearly indicate that spending relatively more time on lowintensity activities affect PAL negatively, whereas highintensity activities does not have much impact on PAL. These findings suggest that reduction of physical inactivity does not necessarily imply high-intensity sports.

The results of this study support previous findings of training intervention studies in the elderly. ${ }^{4,5,13}$ These studies demonstrated that exercise training in an elderly population results in a compensatory decline of non-training physical activity. Morio et al ${ }^{13}$ measured the effect of training on non-training physical activity by using 7 day activity recordings. Non-training physical activity was calculated from the duration and energy costs of the various recorded activities. Goran and Poehlman ${ }^{4}$ calculated non-training physical activity from the difference between total energy expenditure and resting energy expenditure after adjusting for the thermic response to feeding and the energy cost of the exercise training. Meijer et $a l^{5}$ directly measured nontraining physical activity with a tri-axial accelerometer.

The proposed explanation that exercise training fatigues elderly subjects and thus reduces non-training physical activity afterwards, seems too simplistic. Recently, $\mathrm{we}^{5}$ showed that elderly subjects anticipate a training program by lowering their physical activity even before the training session. The training program, two times one hour per week, was of moderate intensity ( $\left.\sim 40 \% \mathrm{VO}_{2 \max }\right)$. Trying to obtain a higher PAL by exercise training counteracts its own effect by the compensatory increase of inactivity. Therefore, it could be argued that exercise training does not affect the mean PAL, at least in an elderly population. Although exercise training has no influence on PAL in an elderly population, it does not mean that exercise training should not be recommended to elderly humans. Following a training program has for example a considerable impact on skeletal muscle. ${ }^{14}$ Coggan et al ${ }^{15}$ demonstrated that exercise training improved maximal oxygen consumption, muscle fiber type composition, capillary density and oxidative capacity of skeletal muscle of 60 to 70 -y-old men and women. Furthermore, Kohrt et al $^{16}$ showed that these changes after following a training program were similar to changes observed in young adults. It has to be mentioned, however, that training cannot completely prevent but only delay the age-related changes of these variables. ${ }^{17}$

It remains speculative, however, why exercise training does not result in an increased PAL since a strong significant association is observed between $\mathrm{VO}_{2 \max }$ and PAL in this study $(r=0.59 ; P<0.0001)$. Brochu et al ${ }^{18}$ recently showed in an elderly population that free-living physical activity associated energy expenditure was significantly related to the peak $\mathrm{VO}_{2 \max }(r=0.42 ; P<0.0001)$. It could be argued that, although a strong positive correlation exists between these two variables, this relationship is not straightforward. To address this point, Dvorak et $a l^{19}$ reported that in an elderly population $(n=117)$, high levels of $\mathrm{VO}_{2 \max }$, independent of physical activity levels, were associated with a more favorable cardiovascular disease risk profile. Additionally, Erikssen et $a^{20}$ showed that even small improvements in $\mathrm{VO}_{2 \max }$ were associated with a lowered risk of death, whereas, Pate et $a l^{1}$ showed that higher levels of PAL were associated with a lower cardiovascular disease profile and overall mortality. These studies support the idea that $\mathrm{VO}_{2 \max }$ and PAL may act in a unique and independent manner to improve cardiovascular and metabolic health in the elderly. A high PAL might be obtained, as shown by the results of the present study, by omitting physical inactivity instead of following an exercise training program.

It could be argued that our results are maybe not entirely generalizable to all older adults. The mean PAL in the present study $(1.65 \pm 0.14)$, however, is in accordance with previous findings. ${ }^{2,21}$ Black et $a l^{2}$ reported for women a mean PAL of $1.69 \pm 23$ in the age group $40-64 \mathrm{y}(n=47)$ and a mean PAL of $1.62 \pm 0.25$ in the age group $65-74 \mathrm{y}(n=24)$. For men mean PAL was $1.64 \pm 0.17$ and $1.61 \pm 0.28$ for the age groups $40-64$ y $(n=15)$ and $65-74$ y $(n=22)$, respectively. Starling et $a l^{21}$ reported a mean PAL of $1.68 \pm 0.28$ in 99 older men and women. The lower mean PAL $(1.58 \pm 0.21)$ observed in the study of Pannemans and Westerterp ${ }^{22}$ compared to the PAL of the present study, could partly be explained by the younger age of the subjects in our study (men $62 \pm 5 \mathrm{y}$ and women $59 \pm 3 y$ vs $71 \pm 5 y$ and $68 \pm 4 y$, respectively). In addition, not all subjects in the present study were retired; nine subjects had still a full-time job (mean PAL 1.73 \pm 0.18 ). Furthermore, the lowest PAL observed in the present study was 1.44 , whereas the lowest PAL in the study of Pannemans and Westerterp ${ }^{22}$ was 1.27 . Therefore, one might assume that the measured PAL reflects the actual physical activity level of an elderly population.

PAL of the elderly was significantly lower than the PAL of the younger adults (Table 2). In another study, we ${ }^{3}$ observed that the decline of $37 \%$ and $35 \%$ in ADMR for women and men, respectively, between the age groups $20-34 \mathrm{y}$ and 
$75+\mathrm{y}$ was mainly a consequence of a substantial reduction in activity-associated energy expenditure. In the present study it was shown that this reduction in activity associated energy expenditure could be explained by a shift from spending more time on low-intensity activities instead of moderate- and high-intensity activities (Figure 2). The elderly spent approximately $17 \%$ more of their time on low-intensity activities than younger adults. From a physiological perspective, elderly wanting to increase their activity level should be recommended to spent less time on lowintensity activities, sitting and standing, and more time on moderate-intensity activities like walking or cycling. This recommendation is in accordance with findings of Pate et $a l^{1}$ who recommended that regular moderate-intensity physical activity provides substantial health benefits.

In conclusion, the findings of this study show that, in the elderly, spending relatively more time on low-intensity activities affects the mean PAL negatively. To obtain a higher PAL does not necessarily imply high-intensity activities like sports.

\section{References}

1 Pate RR, Pratt M, Blair SN, Haskell WL, Macera CA, Bouchard C, Buchner D, Ettinger W, Heath GW, King AC, Kriska A, Leon AS, Marcus BH, Morris J, Paffenberger RS, Patrick K, Pollock ML, Rippe JM, Sallis J, Wilmore JH. Physical activity and public health: a recommendation from the CDC and ACSM. JAMA 1995; 273: $402-407$.

2 Black AE, Coward WA, Cole TJ, Prentice AM. Human energy expenditure in affluent societies: an analysis of 574 doublylabelled water measurements. Eur J Clin Nutr 1996; 50: 72-92.

3 Westerterp KR, Meijer EP. Physical activity and parameters of aging: a physiological perspective. J Gerontol 2001 (in press).

4 Goran MI, Poehlman ET. Endurance training does not enhance total energy expenditure in healthy elderly persons. Am J Physiol 1992; 263: E950-957.

5 Meijer EP, Westerterp KR, Verstappen FTJ. Effect of exercise training on total daily physical activity in elderly humans. Eur J Appl Physiol 1999; 80: 16-21.

6 Bouten CVC, Verboeket van de Venne WP, Westerterp KR, Verduin M, Janssen JD. Daily physical activity assessment: comparison between movement registration and doubly labeled water. J Appl Physiol 1996; 81: 1019 - 1026.

7 Westerterp KR. Physical activity assessment with accelerometers. Int J Obes Relat Metab Disord 1999; 23(Suppl 3): S45 -S49.
8 Westerterp KR, Bouten CVC. Physical activity assessment: comparison between movement registration and doubly labeled water method. Z Ernahrungswiss 1997; 36: 263-267.

9 Siri WE. The gross composition of the body. Adv Biol Med Physiol 1956; 4: $239-280$.

10 Westerterp KR, Wouters L, van Marken Lichtenbelt WD. The Maastricht protocol for the measurement of body composition and energy expenditure with labeled water. Obes Res 1995; 1: $49-57$.

11 Schoffelen PF, Westerterp KR, Saris WHM, Ten Hoor F. A dualrespiration chamber system with automated calibration. J Appl Physiol 1997; 83: 2064-2072.

12 Weir JB. New methods for calculating metabolic rate with special reference to protein metabolism. J Physiol 1949; 109: 1-9.

13 Morio B, Montaurier C, Pickering G, Ritz P, Fellmann N, Coudert J, Beaufrere B, Vermorel M. Effects of 14 weeks of progressive endurance training on energy expenditure in elderly people. Br J Nutr 1998; 80: 511-519.

14 Kirkendall DT, Garrett WE Jr. The effects of aging and training on skeletal muscle. Am J Sports Med 1998; 26: 598-602.

15 Coggan AR, Spina RJ, King DS, Rogers MA, Brown M, Nemeth PM, Holloszy JO. Skeletal muscle adaptations to endurance training in 60- to 70-yr-old men and women. J Appl Physiol 1992; 72: 17801786.

16 Kohrt WM, Malley MT, Coggan AR, Spina RJ, Ogawa T, Ehsani AA, Bourey RE, Martin WHd, Holloszy JO. Effects of gender, age, and fitness level on response of $\mathrm{VO} 2 \mathrm{max}$ to training in 60-71-yr-olds. J Appl Physiol 1991; 71: 2004-2011.

17 Coggan AR, Abduljalil AM, Swanson SC, Earle MS, Farris JW, Mendenhall LA, Robitaille PM. Muscle metabolism during exercise in young and older untrained and endurance-trained men. J Appl Physiol 1993; 75: 2125 - 2133.

18 Brochu M, Starling RD, Ades PA, Poehlman ET. Are aerobically fit older individuals more physically active in their free-living time? A doubly labeled water approach. J Clin Endocrinol Metab 1999; 84: $3872-3876$

19 Dvorak RV, Tchernof A, Starling RD, Ades PA, DiPietro L, Poehlman ET. Respiratory fitness, free living physical activity, and cardiovascular disease risk in older individuals: a doubly labeled water study. J Clin Endocrinol Metab 2000; 85: 957-963.

20 Erikssen G, Liestøl K, Bjørnholt J, Thaulow E, Sandvik L, Erikssen J. Changes in physical fitness and changes in mortality. Lancet 1998; 352: 759-762.

21 Starling RD, Toth MJ, Carpenter WH, Matthews DE, Poehlman ET. Energy requirements and physical activity in free-living older women and men: a doubly labeled water study. J Appl Physiol 1998; 85: $1063-1069$.

22 Pannemans DL, Westerterp KR. Energy expenditure, physical activity and basal metabolic rate of elderly subjects. Br J Nutr 1995; 73: $571-581$ 